\title{
Narrative is Not Emancipatory, but Affective Moments Might Be
}

\author{
LAUREN KAPALKA RICHERME \\ Indiana University (USA)
}

Given that the nature of narrative has gone largely unexamined in music education literature, the purpose of this philosophical inquiry is to consider whether narrative creation and telling might be more inherently liberating or confining than Bowman (2006) suggests. I argue that narratives are ordered, temporarily frozen accounts of complicated prior experiences that individuals justify within prevailing ethical norms. While individuals may feel liberated during the process of forming and telling self-stories, narratives inherently resist emancipation. Subsequently, I examine the nature of affective moments and their relationship with narrative. While both narratives and affect theoryinspired writings represent reality, the latter emphasize sensations and mundane encounters not embedded within a clear plotline. Affective moments serve a crucial purpose in our contemporary precarious and emotionally charged world. Affective moments involve interruption, illuminating the distinction between now and could be. As such, the potential for emancipation, although not necessarily its realization, is an inherent part of affective moments. I end by discussing possible implications for qualitative research, including potential resonances and uncertainties.

Keywords: narrative, affect, philosophy, music education

I

n 2006, Wayne Bowman asked: "What difference will narrative make?” (6). During the intervening years, narrative researchers' honoring of "lived experience as a source of important knowledge and understanding" (Clandinin 2016,17 ) has contributed much to the music education community. In particular, their detailed accountings of stories by individuals from marginalized communities have enhanced the profession's understandings about exclusionary processes. Describing the limits of grand narratives, Margaret Barrett and Sandra Stauffer (2012) explain individual narratives as "a means by which we might trouble certainty, and raise questions concerning the 'taken-for-granted"” (1). By unsettling the assumptions that solidify and homogenize music education practices, narrative researchers can play a key role in current calls for more diversity and inclusivity

(C) Lauren Kapalka Richerme. The content of this article is the sole responsibility of the author. The ACT Journal and the Mayday Group are not liable for any legal actions that may arise involving the article's content, including, but not limited to, copyright infringement. 
within the profession. However, Bowman (2006) notes: "There is nothing inherently emancipatory about narrative" (2).

Narratives are not necessarily credible or trustworthy. According to Bowman (2006), "What narratives offer is not truth in any event, but habitual or convenient ways of describing selves, actions, and events" (11). As such, conducting narrative research necessitates accepting that the meaningful stories that people tell themselves and others may exist at odds with historical facts.

Yet, humans are narrative beings (Bruner 1990), and the stories one creates, tells, and retells compose one's evolving identity (Lieblich, Tuval-Mashiach, and Zilber 1998). Whether as "agents (authors) or audience members (co-authors)," people participate in the making of their own and others' stories (Fisher 1987, 18). Individuals' interconnected, nested stories "live in us, in our bodies, as we move and live in the world" (Clandinin 2016, 22). These narratives interface with the stories of institutions, including schools, providing constantly evolving "plots" (Fisher 1987, 18) that "profoundly shape us all" (Clandinin 2016, 22). It follows that when constructing music education narratives, individuals integrate fact and meaning, observation and interpretation. If one understands an aim of music education research as deepening the profession's understandings about aspects of complex teaching and learning processes, then rigorous examinations and portrayals of teachers' and students' narratives can contribute much to that body of knowledge.

As humans tell and re-tell their narratives, they adapt them to meet their changing life experiences. Bruner (2002) writes that narratives get out-of-date "not just because we grow older or wise but because our self-making stories need to fit new circumstances, new friends, new enterprises" (65). The narratives that the music education profession tells about narrative, including in relation to research, also demand attention and revision in light of contemporary developments and dilemmas.

When Bowman philosophized about narrative in 2006, few could have imagined how much individual and collective storytelling, and their accompanying embodied-emotional responses, would contribute to the polarization of today's political landscapes. Although "the grand narrative has lost its credibility" (Lyotard 1979, 37), contemporary societies increasingly function at the nexus of two or more overarching narratives. For example, one is pro-Brexit or anti-Brexit, in support of the president or prime minister or against them, liberal or conservative. Not only

Richerme, Lauren Kapalka. Narrative is not emancipatory, but affective moments might be. Action, Criticism, and Theory for Music Education 20 (4): 124-45. https://doi.org/10.22176/act20.4.124 
do contrasting formal and informal news outlets create narratives focused on different pieces of information, they also spin opposing narratives out of the exact same report, tweet, or other material. Lyotard (1979) explains: "The narrator's only claim to competence of telling the story is the fact that he has heard it himself. The current narratee gains potential access to the same authority simply by listening” (20).

These overarching narratives influence and in part constitute audience members' own narratives. In Bowman's (2006) terms, what people say and the kinds of things that "society and its power structures (including linguistic ones) encourage or permit them to say" are often synonymous (8). While many narratives within these overarching positions remain untold, these competing societal narratives create discourses that interface with and ultimately constrain those stories. As such, the profession might consider how our current historical moment could inform narrative inquiry processes. Furthermore, since narratives or stories are also used as data in methodologies such as case study and phenomenology (Clandinin 2016), understandings about the nature of narratives may have implications for various qualitative research processes.

There exists an important distinction between the act of telling one's story and the uses to which narratives get put. For Bowman (2006), the nature of narrative processes is neither inherently good nor bad, liberating nor constraining; narratives may free tellers and listeners, but they can just as easily confine them within existing discourses and relations of power. The extent to which narratives emancipate, in the sense of freeing individuals from current ways of thinking, acting, and being that they consider undesirable, depends on how people use them. Bowman (2006) writes: "How the narrative turn is remembered will depend on the uses to which it gets put by music educators and the extent to which those uses change our understandings, beliefs, and ultimately our actions as music educators-and how" (6). I agree that the current and potential future uses of narratives and narrative inquiry necessitate attention, but that is not the primary aim of this inquiry.

Instead, given that the nature of narrative has gone largely unexamined in music education literature, I wonder: Might narratives be more inherently liberating or confining than Bowman (2006) suggests? Building on Bowman, I consider the nature of constructing narratives and assumptions about the "I" who narrates. I then examine the nature of affective moments and their relationship with narrative. It is important to clarify that this is an ontological investigation into the nature

Richerme, Lauren Kapalka. Narrative is not emancipatory, but affective moments might be. Action, Criticism, and Theory for Music Education 20 (4): 124-45. https://doi.org/10.22176/act20.4.124 
of narrative and subsequently into the nature of affective moments, not into the nature of narrative inquiry or other qualitative research processes. I argue that while aspects of narrative inherently resist emancipation, the potential for emancipation, although not necessarily its realization, lies in the affective moment itself. Affective moments serve a crucial purpose in our current precarious and emotionally charged world.

\section{The Nature of Narrative}

Individuals generally understand and tell their narratives sequentially. Constructing a narrative involves choosing which events to include with reference to a clear, ordered storyline. As such, storytellers necessarily emphasize the aspects of an event that best fit the narrative arc.

Yet, there rarely exists a completely clear path or link between current events and past endeavors. While something one did on Monday may impact an occurrence on Wednesday, the accumulation of other intervening moments, habitual practices, and institutionalized power structures also contributed to the latter occurrence. Telling a narrative forces at least partly unrelated events into a clear trajectory. Writing about what he terms the "narrative fallacy," Nassim Nicholas Taleb (2007) explains: "We continuously narrate past events in the light of what appears to make what we think of as logical sense after these events occur" (71). In other words, telling a narrative necessitates an after-the-fact logic that draws connections between initially disconnected or loosely connected moments.

The selection and ordering of events to tell a story inevitably occurs in the present; one chooses past moments in light of current circumstances rather than the circumstances at the time of the event. For example, Taleb (2007) writes that given a surprising election result, media outlets supply voters with a host of fact-checked causes that enable audiences to understand the outcome. While more recently the election stories told by some media outlets have relied on fiction rather than facts, they still provide partisan audiences causal links (albeit imagined) that enable them to understand and frame political outcomes after the fact.

More broadly, Taleb (2007) explains how immediate situations inform memory: "We will tend to more easily remember those facts from our past that fit a narrative, while we tend to neglect others that do not appear to play a causal role in that narrative" (70, emphasis in original). Omitting events that do not fit one's present narrative minimizes how those events may have impacted the individual

Richerme, Lauren Kapalka. Narrative is not emancipatory, but affective moments might be. Action, Criticism, and Theory for Music Education 20 (4): 124-45. https://doi.org/10.22176/act20.4.124 
at the time and thus indirectly contributed to their current stories. Such action also overlooks how, in the face of ever-changing present circumstances, those neglected past events may significantly impact future endeavors.

Take, for example, constructing the narrative that accompanies one's tenure or promotion statement. ${ }^{1}$ While an academic may have judiciously planned and executed a structured research trajectory over the course of five or more years, more often than not, one's work evolves somewhat disjointedly in response to newly found literature, co-authors, or conference needs. In order to construct the narrative statement, the author looks at their body of work and then retrospectively constructs a clear storyline out of projects that may have only tangentially informed one another in the moment. Likewise, when asked to tell a narrative about the abandonment or adoption of certain teaching practices, a music educator naturally selects the moments that most directly explain the transition from past to present. Such action often inadvertently omits the countless other factors that may have contributed to the teacher's changed practices.

Constructing a narrative retrospectively may create a false sense of inevitability. One looks at prior events and then weaves a clear explanation. Making sense of the present involves "forcing a logical link, an arrow of relationship, upon [sequences of facts]" (Taleb 2007, 64, emphasis in original). In seeking convergent meaning-making, one may retrospectively understand events as having a single function. However, in most instances, it is just as likely that the selected series of moments recounted in a narrative could have facilitated other outcomes or have been put to other uses. The drive to explain causal links within narratives "pushes us to think that the world is less random than it actually is" (Taleb 2007, 69). Such action can leave one with an impression of understanding, implying that they could have predicted the present.

However, it is rare that any one description of an event remains permanently solidified. Individuals constantly revisit and revise their self-stories, thus revealing the incomplete, evolving nature of narratives over time. Yet, that does not mean that narrators are necessarily aware of or interested in these alterations. Although certain individuals may have or develop a reflective awareness about their changing narratives, particularly when encouraged for therapeutic or research purposes, such reflection is not an inherent part of the narrative process. Just as one may 
supplant an old social media post with a new one absent attention to their interrelationship, in many instances, a new narrative may replace an old with minimal, if any, reflection.

When constructing a narrative, individuals necessarily make choices about what to include and exclude. Selecting certain aspects of an event to highlight or ignore omits the complexity of all experience. For example, while a single child's question may have served as the final straw that caused a teacher to consider more culturally relevant practices, the question occurred in integration with place-specific affordances and the educator's prior experiences. The alteration also necessitated certain dispositions, some of which the teacher may have begun forming in infancy. As Judith Butler (2005) explains, humans inevitably emerge out of social conditions which they neither control nor fully remember. While the educator might retrospectively select the events that they believe most influential in encouraging their changed practices, one can never fully account for the complicated nature of any single moment.

Nonetheless, a narrator may at times experience the act of telling their story as emancipatory. This feeling of emancipation might result in part from the content of the story (e.g., a shameful secret one felt relieved to reveal), the relationship between narrator and listener (e.g., feeling honored that a particular person wants to hear my story), the self-discovery that occurred during the story-construction process, or the realization that one's narrative remains variable and incomplete. These liberatory feelings, however, exist in tension with the ordered, somewhat fixed nature of all narratives.

When constructing narratives, individuals tend to focus on deviations from daily practices. In Bruner's (1990) words, "The function of the story is to find an intentional state that mitigates or at least makes comprehensible a deviation from a canonical cultural pattern" (49-50). Absent a listener's intervention, narrators rarely center their stories on habitual practices in and of themselves. Writing about the trial of Nazi war criminal Otto Adolf Eichmann, Hannah Arendt (2006) recounts a moment when the examiner asks about a trip that resulted in plans for removing Jews from Slovakia. Eichmann responds by narrating specifics about bowling and drinking with the Slovakian Minister of the Interior. Arendt observes: "To evacuate and deport Jews had become routine business; what stuck in his mind was bowling, being the guest of a Minister, and hearing of the attack on Heydrich" 
(82). ${ }^{2}$ Eichmann's narrative, as told by Arendt, illustrates the tendency to emphasize unexpected encounters rather than repeated daily occurrences, even as extreme as these occurrences may be.

This does not mean that individuals are necessarily unaware of the pervasive socio-political forces that interface with and constitute everyday life. According to Arendt (2006), Eichmann understood his narratives as informed by and in dialogue with Nazi ideology. Likewise, for many individuals, narratives about music teaching and learning necessarily involve forms of institutionalized racism, classism, sexism, homophobia, and ableism. Such narratives often involve either reflections on the socially constructed nature of one's own habits or reactions to others' habits. However, without intervention, the repeated practices that a teacher or student enacts daily but has never questioned rarely play a key role in their selfstories.

Taken together, the qualities of narratives described above suggest that the nature of narratives tends toward confinement rather than emancipation. Constituted by retrospectively selected events that form one or more logical storylines ending-or at least pausing-in the present, narratives temporarily fix and order experiences. They often omit the countless complexities of any given moment as well as unquestioned everyday habits. Though narratives change over time, current self-stories have a tendency to portray one's present position as inevitable, rather than as but one possibility. Without further reflection, narratives may neglect roads not taken, choices not made, the role of random events, and pivotal moments that do not fit one's immediate storyline. One can use a narrative to trouble prevailing practices and may feel liberated because of the reflection and self-discovery needed to tell a certain story, but the narrative itself becomes temporarily frozen in the process. This raises the question: What is the impact of narrative-telling on the narrator?

If narratives are ordered, fixed accounts of complicated prior experiences, then, absent intervention, 3 the act of telling a narrative tends to organize and constrain an individual's sense of self at that time. Bowman (2006) observes: "Discursive and linguistic habits and the social practices in which they are situated shape and constrain both identity and our sense of the possible" (11). Additionally, since narratives rely on existing discourses, any account of oneself invokes societal norms, including ethical ones. Butler (2005) summarizes: “The 'I' does not stand 
apart from the prevailing matrix of ethical norms and conflicting moral frameworks" (7). Just as asking someone not to think of an elephant invokes the image of an elephant, the process of narrating about the need to trouble existing norms necessitates that the storyteller frame their narrative in relation to them.

Moreover, one rarely tells a story in which one views their present thought and action as unethical. Butler (2005) notes that the need to account for oneself in narrative form may even "require a falsification of that life in order to satisfy the criterion of a certain kind of ethics, one that tends to break with relationality" (p. 63). For example, Arendt (2006) recounts how Eichmann expressed that he ultimately desired to serve as a town police chief, but fate destroyed his plans. Arendt explains: "What makes these pages of the examination so funny is that all this was told in the tone of someone who was sure of finding 'normal, human' sympathy for a hard-luck story” (50). While Eichmann's aim for sympathy at a trial addressing his contributions to the mass murder of innocents is an extreme ethical outlier, his narrative reveals the human tendency to portray oneself in prevailing accepted ethical terms.

If humans tend to shape their stories in light of ethical norms, then the act of storytelling typically justifies, rather than challenges, the ethical nature of one's current practices. Those who understand their present practices as ethical, or contort them to appear so, have little incentive to change. If emancipation is understood as freeing individuals from their current undesirable ways of thinking, acting, and being, then the act of narrative-telling rarely has an emancipatory effect on the narrator's ethics.

This does not mean that narratives cannot be used to challenge existing ethical norms. Arendt used Eichmann's story to unsettle thinking about the nature of both evil and democracy, and individuals can use their own and others' stories to problematize what individuals and societies consider ethical. However, in the process of narrating, the narrator is limited not only by the retrospective and fixed nature of narratives but also by the norms necessary for storytelling.

\section{Trading Meaning for Affect}

As detailed in Bruner's (1990) seminal text, Acts of Meaning, the process of meaning-making constitutes the key aspect of narrative production. Bruner summarizes:

Richerme, Lauren Kapalka. Narrative is not emancipatory, but affective moments might be. Action, Criticism, and Theory for Music Education 20 (4): 124-45. https://doi.org/10.22176/act20.4.124 
I believe that we shall be able to interpret meanings and meaning-making in a principled manner only in the degree to which we are able to specify the structure and coherence of the larger contexts in which specific meanings are created and transmitted (64).

In other words, understanding another's narrative necessitates knowledge about the culture-specific contexts that produce and organize meanings.

Interpreting meanings within our own and others' narratives parallels how literary scholars in the 1980 s and 1990 s tended to engage with fictional stories. Hua Hsu (2019) explains that literary criticism used to center on meaning: "The task was interpretation, and the currency was meaning" (62). For example, researchers and readers aimed to understand the meaning of the turtle to which John Steinbeck (1939) devotes a chapter in Grapes of Wrath or the meaning that the sea had for Kate Chopin when writing The Awakening (1899). Yet, in addition to meaningladen narratives, feelings, moods, and atmospheres impact and in part constitute humans' experiences.

In the 2000s, literary scholars increasingly turned away from interpretation and towards affect theory, making it one of their dominant paradigms (Hsu 2019). Since affect theory is more easily experienced than explained, I begin with an excerpt from Lauren Berlant and Kathleen Stewart's (2019) affect theory-inspired book, The Hundreds. 4 In part of a 200-word poem entitled "Bad Feelings," Berlant and Stewart (2019) write:

She reminds me of a woman I met who has trouble being in a room. I stood next to her. We started off pretty well, talking about books and travel and how we knew people, but after twenty minutes we were trapped. I drifted away, releasing us. Over the next three days, we ricocheted off a backlog of social failures; there were furtive looks, the occasional sharp turn on the poolside pavement to avoid contact. No bad feelings but bad feelings were between us, suturing us in a contact aesthetic like my childhood visits to the piano teacher-the earthy oils she wore, the way she ran her hand up the page of music, opening it flat without catching her skin on the staples. ${ }^{5}(31)$

While authors utilizing affect theory purposely resist providing a single, generalizable definition (Gregg and Seigworth 2010), this excerpt illuminates four qualities characteristic of such work.

First, this passage includes sense-laden terms such as failures, sharp turns, and earthy oils. Readers may experience sadness aroused by reading about social failures, an embodied reaction to imagining the jolt of a sharp turn, or an atmos-

Richerme, Lauren Kapalka. Narrative is not emancipatory, but affective moments might be. Action, Criticism, and Theory for Music Education 20 (4): 124-45. https://doi.org/10.22176/act20.4.124 
phere evoked by earthy oils. Berlant and Stewart (2019) link the events not by ordered logic but by shared moods and sensations. Yet, they take care that the affects are not only within the narrator but "between" the narrator and woman. These "forces of encounter" (Gregg and Seigworth 2010, 2) connect individuals while also flowing beyond them. In other words, while an individual's personal feelings may contribute to an affective moment, affect also involves the interplay between feelings or sensations and one's immediate environment. ${ }^{6}$

Second, the excerpt contains multiple motion-filled moments: the initial meeting, the subsequent avoidances, the music lesson. Rather than stagnant images, the authors emphasize movement through words like drift, release, ricocheted, suturing, ran, and opening. Yet, the poem lacks any sort of causality between the piano lesson and the more recent encounters. The motion recalls Brian Massumi's (1995) description of affective encounters as resonant, intense, and vibratory while resisting direction towards a specific end. The ambiguous relationship between these disconnected motion-filled encounters leaves the reader with uncertainty rather than interpretive understanding.

Third, the excerpt focuses not on pivotal transformation but on the mundaneness of everyday encounters. Affect theory-inspired writings highlight immediacy and the "buffeting emotional weather of everyday life" (Hsu 2019, 62). Berlant and Stewart (2019) recount two people meeting in a non-descript room, twenty minutes of small talk, and an uneventful piano lesson. They slow down and attend to seemingly unremarkable moments in a way that reveals both the familiarity and absurdity of habits.

Fourth, beneath the ordinariness lurks a disruptive potential. Affect involves an "in-between" and a capacity "for extending further still" (Gregg and Seigworth 2010, 2). Berlant and Stewart's (2019) poem ends in an uncertain place; the opening of a page suggests a continuation, an entry into other possible relations. Additionally, the narrator enacts freedom through the small subversive act of drifting away from a boring conversation. One might also understand the narrator's and woman's shared awkwardness as a sort of emancipation from the pressure for fluid interactions. These affective encounters illuminate the distinction between now and could be.

Returning to considerations about the nature of narrative, I wonder: What might be the relationship between narratives and affect theory-inspired writing? In order to compare the two, I draw on Barrett and Stauffer's (2012) understanding 
of story as "a means of sense making, a way in and through which we represent, interrogate, and interpret experience and come to know ourselves and others" (1). I examine each of these ideas-represent, interrogate, and interpret experienceindividually.

Like narratives, humans can use affect theory to represent reality. However, more so than narratives, affect theory focuses on sensations. Massumi (1995) argues that narrative objectiveness and matter-of-factness dampen the intensity that constitutes affect. He explains: "An emotional qualification breaks narrative continuity for a moment" (86). For example, in the passage above, Berlant and Stewart (2019) initiate a story about poolside encounters, only to abruptly terminate it by attending to "bad feelings" (31).

Additionally, Massumi (1995) distinguishes emotions used as action-moving elements of a narrative from affect, which "resonates to the exact degree to which it is in excess of any narrative or functional line" (87). While storylines might include emotional moments, affect involves a surplus of emotion experienced apart from any immediate trajectory. For instance, Berlant and Stewart (2019) write about the existence of "bad feelings" without attributing to them a causal role in a specified plot; these feelings have motion, but not directionality. The accumulation of affects may foster new plotlines, but individuals initially experience those sensations absent an immediately obvious storyline. In short, both narratives and affect theory-inspired writings can attend to sensations, but the sensations serve a contrasting function in each. Affect theory-inspired writings, therefore, highlight different aspects of lived experience than do narratives.

Like narratives, affect theory-inspired writings have the potential to interrogate experience. In Hsu's (2019) words: “[Berlant and Stewert's] efforts end up telling us something about what it means to assess our lives without giving up on ourselves" (64). Whether in the form of narrative or affect theory-inspired writing, the act of sharing aspects of one's life necessitates reflection. Although reflection temporarily freezes otherwise motion-filled affective moments, reflection also opens the possibility of interrogation, for both the teller and their audience.

Similarly, both narrative and affect theory-inspired writings can furnish knowledge about self and others. Hsu (2019) writes: "Affect theory provides a way of understanding the sensations and resignations of the present, the normalized exhaustion that comes with life in the new economy" (64). Yet, Hsu's focus on the "present" and "normalized exhaustion" illuminates how the nature of knowledge

Richerme, Lauren Kapalka. Narrative is not emancipatory, but affective moments might be. Action, Criticism, and Theory for Music Education 20 (4): 124-45. https://doi.org/10.22176/act20.4.124 
derived from engaging with affect theory-inspired writings versus narratives may differ. While authors of affect theory-inspired writings typically interrogate the complexities and possibilities of single, often mundane events, authors of narrative-centered writings tend to interrogate the causal connections and relationships among events.

Narrative and affect differ most significantly on the matter of interpretation. Bruner (1990) explains the key role that interpretation plays in narrative processes: "In understanding cultural phenomena, people do not deal with the world event by event or with text sentence by sentence. They frame events and sentences in larger structures.... These larger structures provide an interpretive context for the components they encompass" (64). In other words, one interprets an event within a narrative by referencing both overarching societal structures and the expected structure of a plotline. For example, a researcher might interpret a teacher's decision to start a songwriting class in relation to both prevailing P-12 teaching practices and prevalent professional storylines urging change in pedagogical practices.

Conversely, since affect theory-inspired writing typically involves an immediacy that resists logical connections, it does not automatically demand interpretation against surrounding structures. A reader may posit relationships between the aforementioned piano lesson and poolside encounter, but because Berlant and Stewart (2019) omit any connection, they let "bad feelings" circulate while resisting interpretation. Likewise, the sense-laden experiences that the teacher or students have during a typical day within a songwriting class would serve a key role in research inspired by affect theory.

In summary, while researchers can use both narratives and affect theory-inspired writings to represent reality, the latter emphasizes sensations not embedded within a clear plotline. Both narratives and affect theory-inspired writings can interrogate reality and illuminate understandings, including the sensational aspects of experiences that deepen awareness of self and others. Yet, unlike narrative, affect theory-inspired authors focus on fleeting, often mundane encounters; they refuse the specific story-telling structures and causal links needed for interpretation.

The distinction between narrative and affect is fundamental enough that affect should not be understood as merely a form or aspect of narrative. Yet, there often exists a symbiotic relationship between narrative and affect; narratives can involve affect-laden events, and affective moments inevitably interface with and in part 
constitute one's narratives. Why, then, might music education researchers attend to affect?

\section{Why Affect? Why Now?}

In considering why affect might serve a particularly important role in mid twentyfirst century life, I begin with one of the most stirring constructions of an affective moment that I have recently encountered:

Mom, I did great in school I've worked so hard. Mom, I'm so pleased to tell you, I just got a fantastic job with IBM, I just got a fantastic job with General Motors. I just got- I'm so proud. Mom, a terrible thing just happened. A person who I've never met said that I did things that were horrible and they're firing me from my job, Mom. I don't know what to do. Mom, what do I do? What do I do, Mom? What do I do, Mom? It's a damn sad situation. (Waldman 2018, para. 10)

While these sentences contain a partial storyline, they evoke emotions that exceed a narrow plot. The narrator fosters joy through words like "pleased" and "proud," anger with the claim of capricious injustice, and sympathy through the vulnerable, confused questioning and desire for parental love; the statements conclude with the phrase "sad situation." The repetitions, including "fantastic" and "What do I do?" serves not to further the plot but to build contrasting atmospheres. One can imagine a person of color, LGBTQ individual, immigrant, or members of other historically marginalized communities sharing this story. In actuality, former United States President Donald Trump used this tale as a strategy to garner sympathy for Brett Kavanaugh, a white, economically privileged, private-school educated nominee to the United States Supreme Court during congressional hearings regarding potential prior sexual misconduct.

The aim of creating affect-laden moments constitutes a significant part of contemporary politics that transcends, yet ultimately reinforces, ideological lines. For instance, consider how potential presidential candidates on the American Democratic Party debate stage competed by sharing emotion-filled soundbites about experiencing homophobia, racism, sexism, and the like. While still existing within overarching narratives, these affective moments may carry more sway than the narratives themselves. Similarly, although individual voters may know little about the factual stories surrounding a "caravan of immigrants" or "children in cages," these phrases and their accompanying photographs evoke feelingful responses. The accumulation of everyday affective moments and feelingful responses comes

Richerme, Lauren Kapalka. Narrative is not emancipatory, but affective moments might be. Action, Criticism, and Theory for Music Education 20 (4): 124-45. https://doi.org/10.22176/act20.4.124 
to constitute one's sense of self, ultimately playing an equal or even greater role in decision-making than one's personal narratives.

More broadly, daily rhetoric of all forms teems with affect. People tweet angrily about breakups, share pet and baby pictures meant to evoke laughs, and send text messages with heart, crying, and thumbs up emoji. Although related to one's self story, these short bursts of affect have a certain independence from those narratives. A week from now, a student currently upset by their rating at a choir festival may not include reference to a crying emoji that they just shared in the post that constitutes part of their music education narrative, but today's affective experiences still inform who they are and might become-their self-story.

The sensations that constitute affective moments both make one aware of the present moment's precarious nature and provoke a response. Berlant (2008) explains that affective events involve "scenes that make demands on the sensorium for adjudication, adaptation, improvisation, and new visceral imaginaries for what the present could be" (847). Stated differently, affective moments interrupt habitual practices, forcing one to grapple with a "not yet" future (Gregg and Seigworth 2010, 3).

Experiencing the present and immediate future as uncertain encourages one to consider the option of acting and being differently. For example, music education-related affective moments might involve anxiety about whether or not to honor a student's request or music-making induced joy or frustration that could escalate or dissipate. Teachers and students could respond to affective moments by relying on familiar adaptations and improvisations, thus resisting emancipation. Alternatively, they could lean into the uncertainty of affective moments, perhaps experimenting with the student's request or letting joy or frustration build. Since affective moments are interruptive and precarious, the potential for emancipation, although not necessarily its realization, lies in the affective moment itself. This potential differs from any subsequent emancipatory use made possible by remembering or recounting (narrating) one's own or another's affective moment.

While affective moments have always played key roles in humans' lives, the ever-increasing pervasiveness of social media has made them more prevalent and intense. Hsu (2019) explains that affect theory can frame "uniquely modern questions" including: "Where did the seeming surplus of emotionality that we see on the Internet come from, and what might it become?... What if millennials were un-

Richerme, Lauren Kapalka. Narrative is not emancipatory, but affective moments might be. Action, Criticism, and Theory for Music Education 20 (4): 124-45. https://doi.org/10.22176/act20.4.124 
intelligible to their parents simply because they have resigned themselves to precariousness as life's defining feature?" (64). If research involves gaining a deeper understanding of experience, then researchers need to examine the affective moments that drive multiple aspects of twenty-first century life. Stated differently, understanding contemporary life demands acknowledging affect.

The sensations that affect theory-inspired writing can produce may also reverberate outwards from initial readers or viewers to their surrounding communities. Just as a single tweet can evoke anger or celebration as it spreads across the globe, well-constructed statements within affect theory-inspired research can foster additional affective encounters. Also, since affective moments attend to single, commonplace instances, readers may readily see parallels with aspects of their own experiences.

Another advantage of attending to affective moments is that such action can reveal both the habits and possibilities of everyday life, whether in teaching or researching. When I go to observe student teachers, I come face to face with the mundane activities of teaching: I see the traditional band director ask for better intonation and students who take pride in trying to meet the request. I observe the excitement on a student's face as they take a risk improvising in front of the jazz ensemble, and I witness an overworked yet unwaveringly dedicated educator longingly sip a cup of coffee. I wonder what is lost when researchers omit the senseladen reverberations of everyday habits, including their small deviations, that constitute key aspects of teachers' and students' senses of self.

Alternatively, envision researchers engaging teachers and students with questions such as: What moments moved you the most during the last thirty minutes? To what extent did these occurrences involve a sense of possibility or liberation? If you were to tweet about a moment in this rehearsal, what would you say? These sense-filled descriptions can reveal key aspects of current music education practices, including uncertainties, without directly challenging prior decisions or undermining one's ethical sense of self. As such, they avoid invoking a defensiveness that may discourage teachers and students from speaking frankly about their experiences.

Moreover, musical experiences often involve affects. In group settings, music making typically arouses sensations, including feelings, that extend beyond an individual music maker. ${ }^{7}$ While these affective moments may occur within a larger 
narrative context-be it a rock concert, opera, or month-long composition project-intense musical experiences are often fleeting and unpredictable. While one may not feel chills invoked by a V-I cadence absent the seconds or minutes of suspense that lead to it, the sensation may occur differently or not at all upon a repeat of the musical endeavor. It follows that understanding musical experiences, including educative ones, necessitates embracing the complexity and variability of such ephemeral encounters.

Imagine a qualitative inquiry focused on the four qualities of affective moments detailed above. First, the study setup and analysis might emphasize the sense-filled nature of daily experience. This could include attending to how affects flow through an environment, including between researcher and participants, ${ }^{8}$ as well as participants' embodied-emotional reactions and use of sense-laden discourse. Second, the study could emphasize the role of motion. Participants might consider: How do I move, including physically, relationally, and cognitively-emotionally, within music education and research spaces? Instead of focusing on what caused or resulted from certain movements, participants could attend to the complexities of the movements themselves. Third, participants might slow down unremarkable moments in ways attentive to their complexity, familiarity, and absurdity, without seeking a logical explanation for how one got to that present. Fourth, they could focus on precarious, potentially disruptive moments, regardless of whether or not a different future was realized.

Authors might also experiment with how affect theory-inspired writings, such as Berlant and Stewart's (2019) poems, could inform the portrayal of their research. This might include linking disjointed events through shared moods or sensations, instead of ordered logic. It could also involve aiming to leave the reader with a sense of confusion and interruption.

In sharing some of the possibilities of affect theory-inspired writings I do not mean to negate or undermine the value of narratives. Humans cannot live outside of narratives. Indeed, one could interpret this essay itself as a narrative about affect; I've selected, ordered, and categorized because I cannot escape my own narrative nature. In addition to the near impossibility of writing about affect absent any sort of narrative, affect theory has other notable limits.

Richerme, Lauren Kapalka. Narrative is not emancipatory, but affective moments might be. Action, Criticism, and Theory for Music Education 20 (4): 124-45. https://doi.org/10.22176/act20.4.124 


\section{Limits of Affect and Possible Resonances}

While human cognition and emotion exist inseparably (Damasio 1999), focusing on sensations, rather than logic, highlights their pervasive role in twenty-first century life. Yet, favoring sensations over logic is not without problems. Since contemporary individuals have become "addicted" to having our heartstrings pulled (Hsu 2019, 63), teachers and students may seek out affective moments as ends in themselves. The desire for musical experiences that invoke chills or teaching scenarios filled with honor and praise from students can work at odds with the tendency for affective moments to dislodge future expectations.

A related potential limit of affect theory-inspired writing is that emphasizing embodied-emotional thrills can undermine how those sensations might foster political change (Hsu 2019). In other words, focusing on single affective events may dissuade individuals and groups from considering how they could order those moments into the public stories (Ganz 2007) needed for political action. Similarly, a single affective event may provoke pedagogical change, and yet it takes time and planning to learn new musical or pedagogical practices, institute alternative curricula, or foster connections with one's local and global communities. Systematic changes therefore necessitate more than haphazard collections of affective moments.

Additionally, many of Bowman's (2006) critiques of narrative also hold true for affect theory-inspired writings. Bowman notes: "There are stories that help and stories that hurt. (Often, the same story does both, at once)" (12). While affective moments emphasize the tension between now and could be, they need not lead to more ethical actions. Affective encounters can foster love or hatred, inclusion or exclusion, a sense of heightened responsibility for others or a sense of extreme pride in one's own successes.

Affect theory also provides little assistance regarding questions such as "Whose narratives warrant our professional time and attention, limited as these precious resources are? And whose are better passed over?" (Bowman 2006, 7). While affect theory may encourage added attention to the complexities of sensation-filled everyday common events, it does not provide guidance about how to select among those countless moments and individuals. Affective encounters also still reside inextricable from existing discourses, power-relations, and institutions.

While affect theory-inspired research may have a more emancipatory nature than narratives, the uses to which researchers and communities put them remains

Richerme, Lauren Kapalka. Narrative is not emancipatory, but affective moments might be. Action, Criticism, and Theory for Music Education 20 (4): 124-45. https://doi.org/10.22176/act20.4.124 
a central concern. Bowman's (2006) observation, "Where we fail to tell persuasive stories about the stories that interest us, why they interest us, and what differences they might make-narrative inquiry will remain a professional oddity without real transformative power," (13) also holds true for affect theory-inspired research. How affect theory ultimately impacts the music education profession, as well as musical and educative communities more broadly, will depend on the nature of the encounters, relationships, and societal actions fostered during and after each inquiry.

Despite these limitations, affect theory-inspired writings can reveal key aspects of contemporary life, including that which narratives often omit or obscure. How, then, might researchers undertake such investigations? In agreement with Bowman's (2006) statements about narrative inquiry, affect theory-inspired writings need not rely on a uniform method. Like narrative inquiry, such work resists a single orientation, and "its situatedness and particularity are the very antithesis of method's generality" (Bowman 2006, 12). However, given the similarities between narratives and affect theory-inspired writings, scholarship related to conducting narrative inquiry work might inform research attending to affect theory.

Researchers drawing on affect theory might critically examine their own role, including their ways of being, in the process. The four qualities of resonant work described by Stauffer and Barrett (2009) might serve as starting points for these considerations. They explain such research as respectful, responsible, rigorous, and resilient. Likewise, affect theory-inspired inquiries might demonstrate respectfulness to participants throughout the data gathering process and beyond as well as responsibility for everyone from participants to the profession to the public good; researchers might promote rigor by welcoming and illuminating complexity and foster resilience by troubling certainty and empowering readers.

Considering what the processes of engaging with and sharing affect theoryinspired work might entail, I am left wondering: To what extent might researchers focus on teachers', students', and community members' affective moments in the present versus their recollections of recent affective moments? During or after an affective moment, to what extent will individuals identify potential differing, including towards what they deem more ethical futures, and should researchers ever prompt them for such reflection? How does the notion that affects exist both within and between individuals complicate researcher-participant relationships? How 
might different integrations of narrative and affect theory-inspired writings resonate within various communities, and how can researchers and participants foster more ethical reverberations?

My narrative nature strives to bring this piece to an obvious closure, a denouement. Affect, however, is messy, raw, evolving. It is commonplace yet unfamiliar, meetings and movements but not movement towards or away. Affect, like narrative, is not in itself important or ethical, but on occasion it reveals something about everyday life, as it is and could be. It is sensations that ... interruption.

\section{About the Author}

Lauren Kapalka Richerme is Associate Professor of Music Education at the Jacobs School of Music at Indiana University, where she teaches undergraduate and graduate courses on philosophy, sociology, and instrumental methods, and mentors graduate students' research. Lauren's work has been published in Bulletin of the Council for Research in Music Education, International Journal of Music Education, Journal of Research in Music Education, Philosophy of Music Education Review, Music Education Research, and other journals. Her philosophy book, Complicating, Considering, and Connecting Music Education, in which she explains aspects of poststructuralist philosophy and proposes a poststructuralist-inspired philosophy of music education, is published through Indiana University Press. Lauren currently holds leadership positions in the Indiana Music Educators Association, International Society for the Philosophy of Music Education, and International Society for Music Education. Prior to her university teaching, Lauren taught high school and middle school band and general music in Massachusetts.

\section{References}

Arendt, Hannah. 2006. Eichmann in Jerusalem. New York: Penguin Group.

Barrett, Margaret, and Sandra Stauffer. 2012. Resonant work: Toward an ethic of narrative research. In Narrative soundings: An anthology of narrative inquiry in music education, edited by Margaret S. Barrett and Sandra L. Stauffer, 1-16. New York: Springer Science+Business Media.

Bowman, Wayne. 2006. Why narrative? Why now? Research Studies in Music Education 27 (1): 5-20.

Berlant, Lauren. 2008. Intuitionists: History and the affective event. American Literary History 20: 845-60.

Berlant, Lauren, and Kathleen Stewart. 2019. The Hundreds. Duke University Press.

Richerme, Lauren Kapalka. Narrative is not emancipatory, but affective moments might be. Action, Criticism, and Theory for Music Education 20 (4): 124-45. https://doi.org/10.22176/act20.4.124 
Bruner, Jerome. 1990. Acts of meaning. Cambridge, MA: Harvard University Press.

Bruner, Jerome. 1991. The narrative construction of reality. Critical Inquiry 18 (1): $1-21$.

Bruner, Jerome. 2002. Making stories: Law literature life. Cambridge: Harvard University Press.

Butler, Judith. 2005. Giving an account of oneself. New York: Fordham University Press.

Chopin, Kate. 1899. The awakening. Chicago: Herbert S. Stone \& Company.

Clandinin, D. Jean. 2016. Engaging in narrative inquiry. New York: Routledge.

Clandinin, D. Jean, \& Connelly, F. Michael. 2002. Narrative inquiry: Experience and story in qualitative research. San Francisco: Jossey-Bass.

Damasio, Antonio. 1999. The feeling of what happens: Body and emotion in the making of consciousness. Orlando, FL: Harcourt.

Elliott, David J., and Marissa Silverman. 2012. Rethinking philosophy, re-viewing musical-emotional experiences. In The Oxford handbook of philosophy in music education, edited by Wayne D. Bowman and Ana Lucía Grega, 37-62. New York: Oxford University Press.

Fisher, Walter R. 1987. Human communication as narration: Toward a philosophy of reason, value, and action. Columbia: University of South Carolina Press.

Ganz, Marshall. 2007. Telling your public story: Self, us, now. https://philstesthomepage.files.wordpress.com/2014/05/public-story-worksheeto7ganz.pdf

Gregg, Melissa, and Gregory J. Seigworth. 2010. The affect theory reader. Durham, NC: Duke University Press.

Hsu, Hua. 2019, March 25. That feeling when: What affect theory teaches about the new age of anxiety. The New Yorker, 61-65.

Lieblich, Amia, Rivka Tuval-Mashiach, and Tamar Zilber. 1998. Narrative research: Reading, analysis, and interpretation. Thousand Oaks, CA: Sage Publications, 1998.

Lyotard, Jean-François. 1984. The postmodern condition: A report on knowledge, translation by Geoff Bennington and Brian Massumi. Minneapolis: University of Minnesota Press.

Richerme, Lauren Kapalka. Narrative is not emancipatory, but affective moments might be. Action, Criticism, and Theory for Music Education 20 (4): 124-45. https://doi.org/10.22176/act20.4.124 
Madigan, Stephen. 2011. Narrative therapy. Washington, DC: American Psychological Association.

Massumi, Brian. 1995. The autonomy of affect. Cultural Critique 31: 83-109.

Richerme, Lauren Kapalka. 2018. A Deleuzian reimagining of Susanne Langer's philosophy: Becoming feeling in music education. Music Education Research 20: 330-41. https://doi.org/10.1080/14613808.2017.1409201

Stauffer, Sandra and Barrett, Margaret. 2009. Narrative inquiry in music education: Toward resonant work. In Narrative inquiry in music education: Troubling certainty, edited by Margaret Barrett and Sandra Stauffer, 19-29. New York: Springer Science+Business Media.

Steinbeck, John. 1939. Grapes of wrath. New York: Viking Press.

Taleb, Nassim Nicholas. 2007. The black swan. New York: Random House.

Waldman, Paul. 2018, October 18. Why Trump may actually want Kavanaugh to go down in flames. Washington Post. https://www.washingtonpost.com/blogs/plum-line/wp/2018/10/o3/why-trump-may-actuallywant-kavanaugh-to-go-down-in-flames/

\section{Notes}

${ }^{1}$ I am grateful to Phil Richerme for generating the initial idea for this example. I would also like to thank Phil Richerme for reading a draft of this piece and providing insightful observations.

${ }^{2}$ Reinhard Heydrich was a high-ranking German SS official who Eichmann knew. On May 27, 1942, two Czech agents bombed Heydrich's car. As a result of injuries sustained during the attack, Heydrich died on June 4.

3 For example, therapists sometimes use narrative techniques to assist clients in re-authoring certain limiting self-stories (see, for example, Madigan 2011). Likewise, qualitative researchers may encourage or enable participants to re-author what they formerly understood as a rigid self-story.

4 Berlant and Stewart (2019) never clarify to what extent their poems or "makings" are taken from the personal recollections versus imagined experiences. They explain them as "exercises in following out the impact of things (words, thoughts, people, objects, ideas, worlds) in hundred-word units or units of hundred multiples" (ix). In a chapter entitled "Writing Life," they hint at the autobiographical nature of their work: "But slowly, under the velocities of worldy reals that came and went, I learned to write in my own skin, like it or not" (10). However, since

Richerme, Lauren Kapalka. Narrative is not emancipatory, but affective moments might be. Action, Criticism, and Theory for Music Education 20 (4): 124-45. https://doi.org/10.22176/act20.4.124 
Bruner (1991) suggests that narratives can include elements of fantasy, even if Berlant and Stewart do not aim for strict recollections of events, their process is not antithetical to that of narrative construction.

5 Berlant and Steward (2019) end each poem with a parenthetical list of what appear to be inspirations for the piece. "Bad Feelings" is followed by the following "(Contact aesthetic; Contagion; Gibbs 2006, 2011; Pine 2012, 2016)" (31).

${ }^{6}$ For a detailed description of how philosophers Gilles Deleuze and Félix Guattari distinguish between affects and feelings as well as possible applications of these ideas to music education see Richerme (2018).

${ }_{7}$ See, for example, Elliott and Silverman (2012).

8 Since the relationship between researcher and participants in narrative inquiry is collaborative (Clandinin and Connelly 2002), it is problematic to draw a strict divide between researchers and participants. In order to avoid reinforcing this divide, I use the word "participants" to mean both researchers and participants for the remainder of this paragraph.

Richerme, Lauren Kapalka. Narrative is not emancipatory, but affective moments might be. Action, Criticism, and Theory for Music Education 20 (4): 124-45. https://doi.org/10.22176/act20.4.124 